\title{
Short-term hyperglycaemia causes non-reversible changes in arterial gene expression in a fully 'switchable' in vivo mouse model of diabetes
}

\author{
S. Zervou • Y.-F. Wang • A. Laiho • A. Gyenesei • \\ L. Kytömäki • R. Hermann • S. Abouna • D. Epstein • \\ S. Pelengaris • M. Khan
}

Received: 2 April 2010 /Accepted: 2 August 2010 / Published online: 16 September 2010

(C) Springer-Verlag 2010

\begin{abstract}
Aims/hypothesis Irreversible arterial damage due to early effects of hypo- or hyperglycaemia could account for the limited success of glucose-lowering treatments in preventing cardiovascular disease (CVD) events. We hypothesised that even brief hypo- or hyperglycaemia could adversely affect arterial gene expression and that these changes, moreover, might not be fully reversible.

Methods By controlled activation of a 'switchable' c-Myc transgene in beta cells, adult $\mathrm{pIns}$-c-MycER ${ }^{\mathrm{TAM}}$ mice were rendered transiently hypo- and then hyperglycaemic, after
\end{abstract}

Electronic supplementary material The online version of this article (doi:10.1007/s00125-010-1887-5) contains supplementary material, which is available to authorised users.

\section{S. Zervou}

Department of Cardiovascular Medicine,

Wellcome Trust Centre for Human Genetics, University of Oxford,

Oxford, UK

S. Zervou $\cdot$ Y.-F. Wang $\cdot$ S. Abouna $\cdot$ M. Khan $(\bowtie)$

Biomedical Research Institute,

Department of Biological Sciences, University of Warwick,

Coventry CV4 7AL, UK

e-mail: michael.khan@warwick.ac.uk

A. Laiho $\cdot$ A. Gyenesei $\cdot$ L. Kytömäki $\cdot$ R. Hermann

GenoSyst,

Turku, Finland

D. Epstein

Department of Mathematics, University of Warwick,

Coventry, UK

\section{S. Pelengaris}

Warwick Medical School, University of Warwick,

Coventry, UK which they were allowed to recover for up to 3 months. Immediate and sequential changes in aortic global gene expression from normal glycaemia through hypo- and hyperglycaemia to recovery were assessed.

Results Gene expression was compared with that of normoglycaemic transgenic and tamoxifen-treated wildtype controls. Overall, expression of 95 genes was significantly affected by moderate hypoglycaemia (glucose down to $2.5 \mathrm{mmol} / \mathrm{l}$ ), whereas over 769 genes were affected by hyperglycaemia. Genes and pathways activated included several involved in atherogenic processes, such as inflammation and arterial calcification. Although expression of many genes recovered to initial pre-exposure levels when hyperglycaemia was corrected $(74.9 \%)$, in one in four genes this did not occur. Quantitative reverse transcriptase PCR and immunohistochemistry verified the gene expression patterns of key molecules, as shown by global gene arrays.

Conclusions/interpretation Short-term exposure to hyperglycaemia can cause deleterious and persistent changes in arterial gene expression in vivo. Brief hypoglycaemia also adversely affects gene expression, although less substantially. Together, these results suggest that early correction of hyperglycaemia and avoidance of hypoglycaemia may both be necessary to avoid excess CVD risk in diabetes.

Keywords Aorta · Cardiovascular · Diabetes · GeneChip arrays $\cdot$ Hyperglycaemia $\cdot$ Mouse
Abbreviations
CVD Cardiovascular disease
VCAM Vascular cell adhesion molecule
VEGF Vascular endothelial growth factor 


\section{Introduction}

Hyperglycaemia has long been the prime suspect for accelerated cardiovascular disease (CVD) in type 2 and type 1 diabetes [1-4]. Large epidemiological and clinical studies suggest that blood glucose levels predict risk of CVD [3, 5-7], in the presence and absence of other CVD risk factors as reviewed by Middelbeek and Horton [8], and even in prediabetic states [9]. Moreover, CVD risk in middle age may be similar in type 2 and type 1 diabetes patients (in whom the cardio-metabolic syndrome is usually absent) [10]. However, in randomised clinical trials, glucose-lowering treatments have had little impact on CVD risk [11, 12]. Thus questions have been raised about whether hyperglycaemia is a genuinely modifiable CVD risk factor.

The effects of high glucose on gene expression and protein levels have been described in various cell-types in vitro [13-17]. However, few studies have addressed effects of hyperglycaemia in vivo [18-20]. Despite providing much important information, these studies have largely used traditional animal models, such as NOD mice and $d b$ / $d b$ mice for type 1 and type 2 diabetes mellitus respectively $[21,22]$, in which onset of hyperglycaemia is unpredictable and irreversible [23-25], or associated with potentially confounding CVD risk factors, such as dyslipidaemia or drug treatments.

To overcome these limitations, we used $\mathrm{pIns-c-MycER^{ \textrm {TAM } }}$ transgenic mice $[26,27]$ to investigate molecular changes in the artery caused by hyperglycaemia in vivo. In these mice, activation of a 'switchable' c-Myc chimeric protein in pancreatic beta cells induces loss of differentiation and apoptosis, resulting in predictable onset of hyperglycaemia. Importantly, as deactivation of Myc is followed by redifferentiation and regeneration of beta cells, we were able to study recovery from hyperglycaemia without the confounding effects of glucose-lowering agents. As these mice are free of dyslipidaemia and obesity, we were also able to isolate effects of hyperglycaemia. Given current interest in the atherogenic effects of hypoglycaemia [28, 29], another interesting feature of this model is that a brief period of hypoglycaemia occurs at around $24 \mathrm{~h}$ after Myc activation, from which mice fully recover and which can also be examined before the subsequent development of hyperglycaemia.

We therefore first sought to define the early effects of hypoglycaemia and then of hyperglycaemia on molecular changes in the artery of pIns-c-MycER ${ }^{\mathrm{TAM}}$ mice in vivo. We then sought to identify which of the genes affected were reversed after short- and long-term recovery time-points once glycaemia had been corrected.

\section{Methods}

Transgenic mice

Mice ( $\mathrm{p}$ Ins-c-MycER ${ }^{\mathrm{TAM}}$ ) were generated as previously published [26, 27]. Our experiments were performed in female mice that were 3 to 6 months of age, inbred into CBA-C57Bl/6 background (B\&K International, Hull, UK) and maintained under barrier conditions. Although previous studies with $\mathrm{pIns}$-c-MycER ${ }^{\mathrm{TAM}}$ mice have shown no significant sex-related differences in duration of glycaemia and recovery, our use of female mice only minimised variation in gene expression due to age, sex or strain.

\section{Experimental design}

c-MycER ${ }^{\text {TAM }}$ protein is activated in pancreatic beta cells of adult transgenic mice ( $\mathrm{p} I n s-\mathrm{c}-\mathrm{MycER}^{\mathrm{TAM}}$ ) by daily intraperitoneal administration of tamoxifen (TAM; SigmaAldrich, Poole, UK) (1 mg/0.2 $\mathrm{ml}$ in peanut oil) [27]. Inactivation of c-MycER ${ }^{\text {TAM }}$ protein was achieved through withdrawal of tamoxifen. All protocols conformed to UK Home Office regulations and local Ethical Committee standards. Mice were treated with tamoxifen for up to 7 days (Myc 'ON') and then monitored during recovery for more than 4 months (140 days) (Myc 'OFF'). Experimental time-points were: c-Myc 'ON'; Day 2 (hypoglycaemia), Day 4 (recovery from hypoglycaemia), Day 7 (hyperglycaemia); c-Myc 'OFF'; Day 11 (early recovery from hyperglycaemia), Day 26 (longer term recovery from hyperglycaemia). Each time-point involved replicate experiments in at least three mice (up to 6). As a further control experiment for effects of tamoxifen, wild-type mice and matching transgenic c-MycER ${ }^{\mathrm{TAM}}$ mice $(n=3$ per group) were given tamoxifen for up to 7 days.

Isolation of aorta

Mice were killed by cervical dislocation. The thoracic cavity was opened rapidly and blood washed off prior to arterial arch extraction and snap-freezing in liquid nitrogen for RNA extraction. The abdominal fragment of the artery was fixed in $4 \%$ (wt/vol.) paraformaldehyde for immunohistochemistry.

Serum collection

Terminal blood collected from the right ventricle was left to coagulate for $30 \mathrm{~min}$ at room temperature and then centrifuged for $3 \mathrm{~min}$ at $10,000 \mathrm{~g}$. Supernatant fractions were collected for biochemical analysis. 
Biochemical assays Blood glucose levels were monitored daily at the same time of day during free access to food using glucose monitoring strips (Accuchek; Roche Diagnostics, Burgess Hill, UK). Lipids and NEFA were measured in serum, using a lipid profile test system (Cholestech L.D.X; Cholestech, Point of Care Services, Swindon, UK) and NEFA C system (Wako, Alpha Labs, Eastleigh, UK), respectively.

\section{GeneChip microarray analysis}

Total RNA was extracted from arteries using a kit (RNEasy Plus Mini-Kit; Qiagen, Crawley, UK) as described previously [30]. For this purpose, three mice were used per timepoint, each mouse being analysed individually without pooling of RNA (as in gene expression data analysis below).

Hybridisation to Affymetrix GeneChip arrays A two-cycle protocol was performed at the beginning of our gene array analysis. Double-amplified biotin-labelled cRNA $(10 \mu \mathrm{g})$ was hybridised to Affymetrix MOE430 2.0 GeneChips (Affymetrix, High Wycombe, UK) together with prelabelled hybridisation controls according to the Affymetrix GeneChip Expression Analysis Technical Manual. Gene expression data, pattern and functional enrichment analyses were performed as described before [31] (see Electronic supplementary material $[\mathrm{ESM}])$.

\section{Quantitative reverse transcriptase PCR}

Total RNA (100-200 ng) from arterial arch samples (used in the global gene array analysis) was also used to synthesise cDNA (Applied Biosystems, Warrington, UK) prior to quantitative PCR. Amplification was performed on the Roche Light Cycler (Roche, UK), using specific oligonucleotides, as shown on ESM Table 1. For quantifica- tion purposes, $G A P D H$ was used as reference gene. Results were analysed individually per mouse $(n=3$ mice per timepoint) using the $2^{-\Delta \Delta \mathrm{C}_{\mathrm{t}}}$ method [32]. Normalised gene expression levels were compared with levels for Day 0.

Immunohistochemistry

Methods were followed as previously described for cryosections [27]. Antibodies were provided by either Santa Cruz Biotech (Insight Biotech, Wembley, UK) or Dako (Ely, UK). Immunostained sections were analysed using a confocal microscope (SP2; Leica Microsystems Milton Keynes, UK) with attached image-capturing software.

\section{Results}

Blood glucose levels, pIns-c-MycER ${ }^{\mathrm{TAM}}$

For the purpose of our experiment, data from at least three replicate experiments per time-point are plotted in Fig. 1. On Day 0 , blood glucose levels were around $5 \mathrm{mmol} / \mathrm{l}$, with a clear decrease down to $2.5 \mathrm{mmol} / \mathrm{l}$ (and no lower) during the first $24 \mathrm{~h}$ of c-Myc activation (brief hypoglycaemia window). Blood glucose levels increased from Day 2, peaking at $>25 \mathrm{mmol} / \mathrm{l}$ on Day 7 . Blood glucose levels fell rapidly following Myc deactivation and were largely normalised at 3 weeks, by which time glucose levels were identical to those of wild-type littermates. Glucose levels remained slightly above mean pre-treatment levels, which, as previously shown, are generally slightly lower than average for wild-type mice [33]. Importantly, transgenic and wild-type mice had an essentially normal response to glucose tolerance tests on Days 26 and 57 (3 weeks after cMyc was 'switched off') (ESM Fig. 1).

As expected, c-Myc-induced suppression of insulin expression and destruction of beta cells was mirrored by the acute onset and maintenance of hyperglycaemia [27], with similar kinetics in female and male mice (data not shown for
Fig. 1 Blood glucose (nonfasted). Activation of c-Myc (c-Myc 'ON') and recovery (during c-Myc 'OFF') as indicated for (a) up to 4 months and (b) shorter recovery up to 19 days. Glucose values of at least three mice are shown per time point

\section{a}

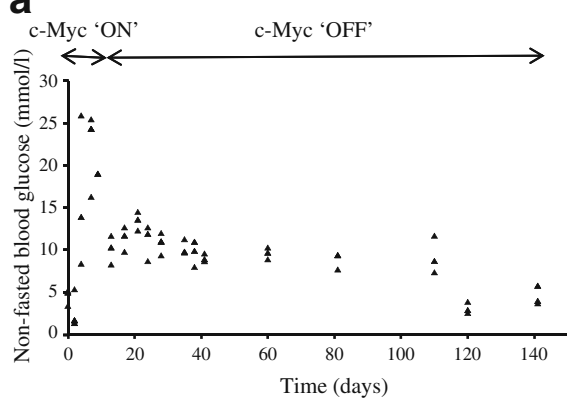

b

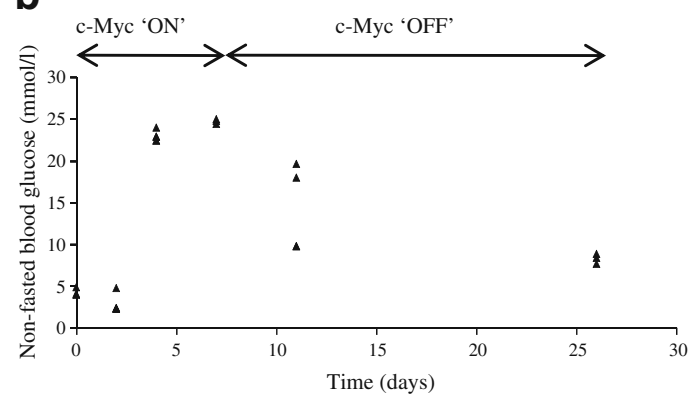


males). In line with this, the results obtained here were not influenced by the oestrous cycle in female mice. Wild-type mice that were treated by tamoxifen displayed blood glucose levels ranging from about 6 to 9 mmol/l (ESM Fig. 2).

Cholesterol, triacylglycerol and NEFA levels

HDL, total cholesterol, triacylglycerol and NEFA were measured in serum from Day 0 to Day 57 ( $n=3$ per timepoint) (Fig. 2). The first three remained unchanged when Day 0 was compared with Day 7 , while NEFA concentrations were marginally affected at peak hyperglycaemia.

\section{Global GeneChip arrays}

Using Genespring GX 10.0 (Agilent Technologies, Wokingham, UK) we identified changes in gene expression by a magnitude of twofold on Day 7 (peak of glycaemia) and the presence/lack of ability to reverse by Day 26 (the longest recovery time-point available for GeneChip Array analysis). Gene expression profiles for total, reversed and non-reversed genes (Fig. 3a-c) were generated. Array data were submitted to NCBI's GEO (Accession No. GSE15401; www.ncbi.nlm.nih.gov/geo/query/acc.cgi?acc=GSE15401, accessed 9 August 2010).

Genes regulated by tamoxifen in normoglycaemic control mice In control wild-type mice treated with tamoxifen, 12 genes were differentially expressed when compared with $\mathrm{c}^{-M y c E R}{ }^{\mathrm{TAM}}$ up to Day 7 (ESM Fig. 3); for full list of genes, see ESM Table 2. Of the genes affected by tamoxifen, 20 were common to those altered by hyper- glycaemia (18 genes) and hypoglycaemia (two genes) (ESM Table 3). No genes from this group appear in of the rest of our data analyses.

Gene changes caused by hypoglycaemia Changes in 95 genes were attributed to the brief hypoglycaemic phase (ESM Fig. 4; Pathway analysis).

Gene changes at the peak of hyperglycaemia (Day 7) At Day 7 the expression of 769 genes was altered by more than twofold (up- or downregulated) due to hyperglycaemia $(p \leq 0.05)$ (Tables 1 and 2). Importantly, among the 769 altered genes at Day 7 vs Day 0, (Fig. 3a), the changes were reversed in $576(74.9 \%)$ genes by Day 26 (Fig. 3b), whereas in the $67(25.1 \%)$ other genes they were not reversed within the same time (Fig. 3c).

Enrichment analyses identified the following genes that changed substantially and closely mirrored changes in blood glucose levels: (1) exclusively upregulated on Day 7: cytoskeletal calmodulin, titin (Ttn), desmoplakin, thrombospondin 2 (Thbs2), protocadherin7 ( $P c d h 7)$, phosphodiesterase 1A (Pdela), retinoic acid receptor responder 2 (Rarres2), adenylate kinase $3(A k 3)$, integrin $\beta 5$ (Itgb5), endothelin receptor A (Ednra), laminin $\gamma 1$ (Lam $\gamma 1$ [also known as Lamc1]), osteoglycin (Ogn), caspase 12 (Casp12), angiopoietin 2 (Angpt2); (2) downregulated: myosin VB (Myo5a), myosin light chain kinase (Mylk3), troponin I (TnnI [also known as Tnnil]), myosin heavy polypeptide (Myh [also known as Mutyh]), keratin 13 (Krt13).

Gene ontology enrichment analysis using PatternViewer (GenoSyst, Turku, Finland) revealed that the above list includes genes involved in lipid metabolism (ESM Fig. 5,
Fig. 2 Lipid profile for pIns-MycER ${ }^{\mathrm{TAM}}$ mice, with (a) HDL, (b) total cholesterol, (c) triacylglycerol and (d) NEFA. Results from these assays correspond to three replicates per time-point
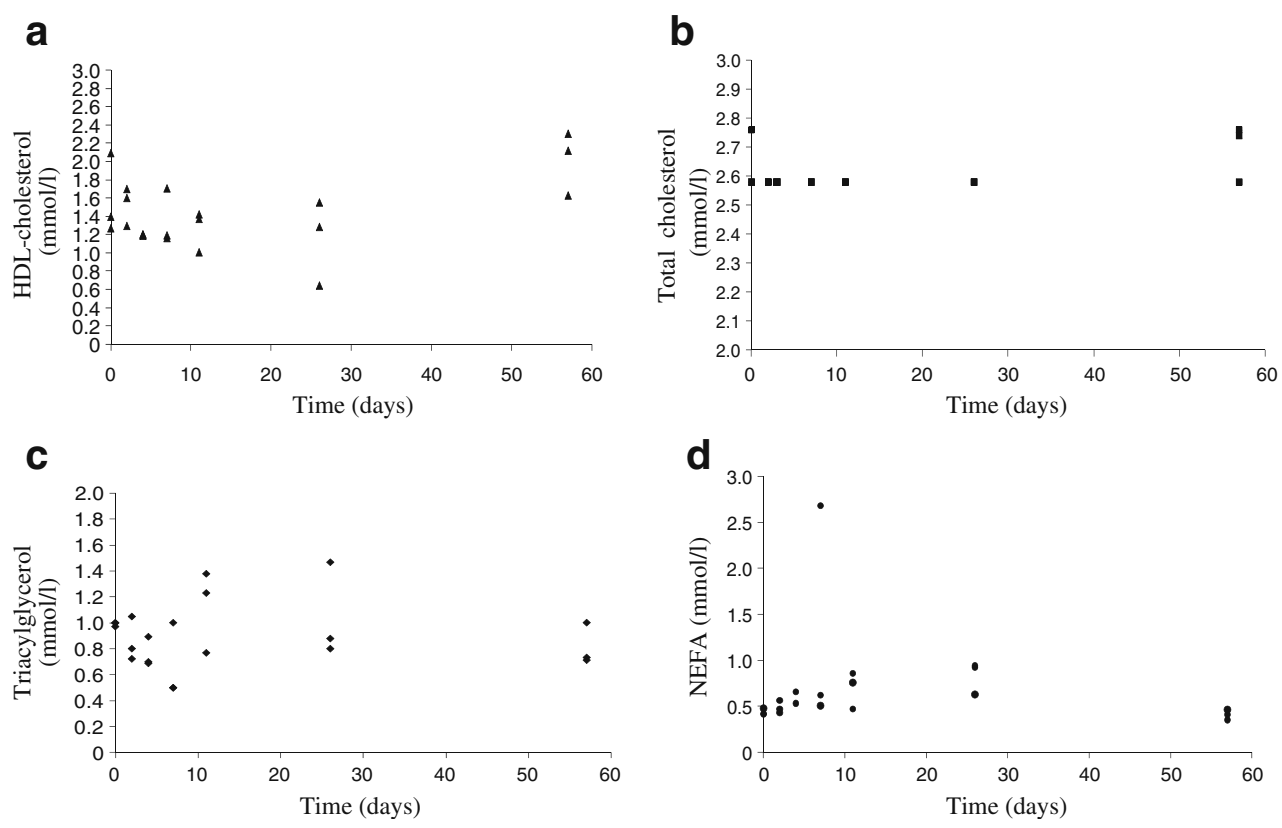

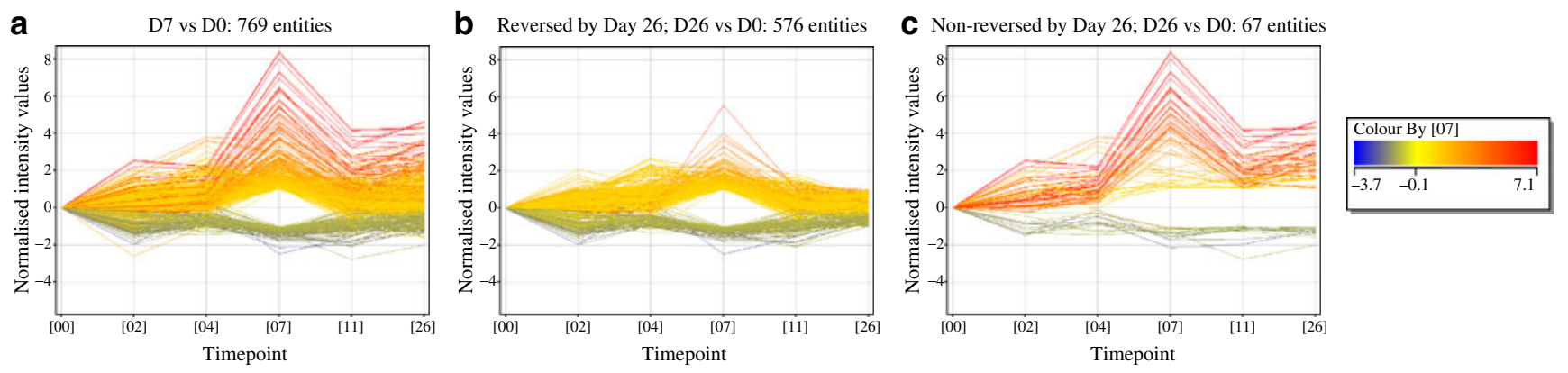

Fig. 3 Gene expression profiles from Genespring GX 10.0 (Agilent) showing expression for all altered genes. a Altered genes $(n=769)$ on Day 7 vs Day 0, with 647 genes up- and 122 genes downregulated. b Reversed genes on Day $26(n=576)$ vs Day 0. c Non-reversed genes on Day 26 vs Day 0 ( $n=67$ consisting of 53 of the upregulated and 14

ESM Table 4). These genes were downregulated by up to twofold from Day 2 through to Day 26.

Genes involved in arterial calcification A total of 13 genes implicated in arterial calcification and premature atherosclerosis were differentially expressed due to hyperglycaemia, but all reverted to basal levels by Day 26 (listed in Table 1 and ESM Fig. 6).

of the downregulated genes). Tamoxifen-affected genes were excluded. Results derived after unpaired Student's $t$ test, $p \leq 0.05$. Intensity normalised by $\log _{2}$. Colour scale red to blue, highest through to lowest expression, respectively

Genes that recover after restoration of normoglycaemia In addition to the calcification-related genes, examples of other genes that recovered after normalisation of blood glucose levels are shown in Tables 1 and 2 (576 genes in total). Upregulated genes on Day 7 included: (1) cell cyclerelated cyclin D2 (Ccnd2) and insulin growth factor 1 (Igf1); (2) cell adhesion molecules vascular cell adhesion molecule (Vcaml) and matrix metalloproteinases (Mmp3
Table 1 Examples of genes that were altered on Day 7 and were either reversed or nonreversed by Day 26 compared with Day 0

All genes listed were altered on Day 7; absolute fold change is shown in addition to $p$ value for Students' $t$ test, corresponding to significance levels for Day 7 compared with Day 0

Tamoxifen-affected genes were excluded

\begin{tabular}{|c|c|c|c|}
\hline Gene symbol by status & Gene name & Fold change & $p$ value \\
\hline \multicolumn{4}{|l|}{ Reversed } \\
\hline Vcam1 & Vascular cell adhesion molecule 1 & 2.35 & $1.38 \times 10^{-3}$ \\
\hline Mmp 9 & Matrix metalloproteinase 9 & 2.05 & $3.64 \times 10^{-3}$ \\
\hline Hsp90b1 & Heat shock protein 90 , beta member 1 & 2.63 & $1.16 \times 10^{-3}$ \\
\hline Jun & Jun oncogene & 2.5 & $2.92 \times 10^{-3}$ \\
\hline $\operatorname{Veg} f c$ & Vascular endothelial growth factor homolog & 2.41 & $8.06 \times 10^{-3}$ \\
\hline$V w f$ & von Willebrand factor & 3.33 & $2.01 \times 10^{-5}$ \\
\hline Fabp7 & Fatty acid binding protein 7 , brain & -5.62 & $2.73 \times 10^{-4}$ \\
\hline Kcnq2 & Potassium voltage-gated channel, subfamily Q & -2.11 & $3.34 \times 10^{-4}$ \\
\hline \multicolumn{4}{|l|}{ Calcification-related } \\
\hline Bmpr2 & Bone morphogenic protein receptor, type II & 2.07 & $2.10 \times 10^{-3}$ \\
\hline Mmp3 & Matrix metalloproteinase 3 & 2.78 & $5.10 \times 10^{-3}$ \\
\hline Wifl & Wnt inhibitory factor 1 & 2.46 & $1.38 \times 10^{-2}$ \\
\hline Ccnd2 & Cyclin D2 & 3.89 & $6.97 \times 10^{-4}$ \\
\hline Bves & Blood vessel epicardial substance & 2.2 & $1.74 \times 10^{-2}$ \\
\hline Omd & Osteomodulin & 2.47 & $1.04 \times 10^{-4}$ \\
\hline \multicolumn{4}{|l|}{ Non-reversed } \\
\hline$C k m$ & Creatine kinase, muscle & 11.23 & $2.89 \times 10^{-4}$ \\
\hline Tnnt2 & Troponin T2, cardiac & 339.25 & $3.39 \times 10^{-7}$ \\
\hline Myoz2 & Myozenin 2 & 24.95 & $1.66 \times 10^{-6}$ \\
\hline Fos & FBJ osteosarcoma oncogene & 2.54 & $3.32 \times 10^{-4}$ \\
\hline$P \ln$ & Phospholamban & 23.12 & $2.33 \times 10^{-4}$ \\
\hline Colla1 & Collagen, type I, alpha 1 & 2.13 & $1.45 \times 10^{-3}$ \\
\hline Plg & Plasminogen & -2.64 & $5.09 \times 10^{-4}$ \\
\hline Fabpl & Fatty acid binding protein 1 , liver & -2.55 & $3.02 \times 10^{-5}$ \\
\hline
\end{tabular}


Table 2 Summary of changes in all entities on Day 7 compared with Day 0

\begin{tabular}{|c|c|c|c|c|}
\hline Day 7 & Day 11 & Day 26 & Definition & Entities $(n)$ \\
\hline \multirow{9}{*}{ Up $n=647$} & \multirow{3}{*}{ Remained up } & Remained up & Non-reversed & 53 \\
\hline & & Back to basal level & Reversed & 34 \\
\hline & & Reversed to lower than basal level & & 1 \\
\hline & \multirow[t]{3}{*}{ Back to basal level } & Went up & & 103 \\
\hline & & Back to basal level & Early reversed & 453 \\
\hline & & Went down & & 2 \\
\hline & \multirow[t]{3}{*}{ Reversed to lower than basal } & Turned to higher than basal level & & 0 \\
\hline & & Back to basal level & & 1 \\
\hline & & Remained down & & 0 \\
\hline \multirow[t]{9}{*}{ Down $n=122$} & \multirow[t]{3}{*}{ Turned to higher than basal } & Remained up & & 0 \\
\hline & & Back to basal level & & 0 \\
\hline & & Reversed to lower than basal level & & 0 \\
\hline & \multirow[t]{3}{*}{ Back to basal level } & Went up & & 0 \\
\hline & & Remained at basal level & Early reversed & 53 \\
\hline & & Went down & & 17 \\
\hline & \multirow[t]{3}{*}{ Remained down } & Turned to higher than basal level & & 2 \\
\hline & & Back to basal level & Reversed & 36 \\
\hline & & Remained down & Non-reversed & 14 \\
\hline
\end{tabular}

Includes information on reversal; the pattern followed by each group of entities is also described, in addition to the numbers of entities in each group Total entities $n=769$, reversed entities $n=576$, non-reversed entities $n=67$

$p \leq 0.05$, Student's $t$ test

and $M m p 9$ ); and (3) atherosclerosis-related von Willebrand factor ( $V w f)$, apolipoprotein D (Apod), Jun, Myh6 and heatshock protein $H s p 90 b 1$. Downregulated genes on Day 7 included: fatty acid binding protein 7 ( Fabp 7$)$ and potassium voltage-gated channels (Kcnh3 and Kcnq2). Pathway analysis showed a pivotal role in biological processes for the oncogene Jun in chondrogenesis, supporting an osteogenic profile, which was caused by transient hyperglycaemia. Also, Igfl leads to tissue growth and proliferation; other processes affected were those involving the potentially atheroprotective phospholipase Pla2g4a, which is responsive to hypoxia (ESM Fig. 7).

Non-reversed genes A group of genes $(n=67)$ that were altered on Day 7 due to hyperglycaemia failed to return to basal expression levels by Day 26 (Tables 1 and 2). Examples of non-reversed genes by Day 26 were: angiogenin (Ang1), prostaglandin-associated genes Hpdg and Alox 15, the apolipoprotein B (Apobec 1) gene and cell turnover-associated proteins such as: (1) the upregulated FBJ osteosarcoma gene Fos, creatine kinase $(\mathrm{Ckm})$, cardiac troponins $T n n 2$ and $T n n 3$, and early growth response 3 (Egr3); and (2) the downregulated fatty acid binding proteins 1 and 4 (Fabpl and Fabp4), and plasminogen (Plg) (Tables 1 and 2). The expression of some genes was dramatically elevated at the peak of hyperglycaemia compared with others. Examples are the cardiac troponin 2 and 3 (Tnn2, Tnn3) genes (upregulated by more than 255- and 56-fold, respectively), Ttn (122-fold upregulation) and small muscle protein (Smpx) with a 43-fold increase on Day 7 (Tables 1 and 2, ESM Fig. 8).

Pathway analysis

The networks of genes that changed at the peak of hyperglycaemia included pro-inflammatory genes such as S100, the chemokine C-X-C motif and prostaglandin $\mathrm{H}$ synthase-2 (Pghs-2 [also known as Ptgs2]) (ESM Figs 6-8), as well as genes related to oxidative stress such as paraoxonase 1 (Ponl) and apolipoprotein d (Apod). Many of these changes due to hyperglycaemia were related to genes involved in endothelial cell dysfunction such as $V w f$, Vcam1 and smooth muscle cell-related genes like Tnn2 and myozenin 2 (Myoz2) (Table 1).

Examination of the non-reversed genes suggested ongoing tissue remodelling, with Egrl contributing to a wound-healing and protective mechanism, while Egr3 is involved in cell turnover (apoptosis or proliferation). Furthermore, plasminogen (Plg) promotes angiogenesis, while Fos is potentially involved in tissue modification towards an osteogenic profile of the artery (ESM Fig. 8). The different patterns of gene expression changes are summarised in Table 2. 
Table 3 Fold changes of the 30 entities forming the overlap between the genes that changed during hypoglycaemia and those that changed at peak glycaemia (Day 7)
Fold changes were normalised for $\log _{2}$

\begin{tabular}{|c|c|c|c|c|c|c|}
\hline Gene symbol & Day 0 & Day 2 & Day 4 & Day 7 & Day 11 & Day 26 \\
\hline Apod & 0 & 1.474 & 1.1003 & 2.066 & -0.026 & 0.2805 \\
\hline Sncg & 0 & -1.6411 & -1.165 & -1.76 & -2.197 & -0.537 \\
\hline Cxcl13 & 0 & 3.213 & 4.079 & 3.976 & 2.837 & 2.333 \\
\hline Akapl & 0 & -1.364 & -0.848 & -1.614 & -1.6259 & -0.5702 \\
\hline Comp & 0 & 1.283 & 0.755 & 1.956 & 0.8939 & 0.89338 \\
\hline Fabp 4 & 0 & -1.799 & -0.337 & -2.2898 & -2.1526 & -1.21554 \\
\hline Ifitm 1 & 0 & 1.428 & 0.8188 & 1.053 & 0.927 & 0.10867 \\
\hline$I g j$ & 0 & 4.825 & 6.723 & 6.424 & 3.489 & 6.813 \\
\hline Itpr 2 & 0 & -1.0154 & -0.613 & -1.177 & -0.8731 & -0.50457 \\
\hline Acsm3 & 0 & -1.288 & -0.3705 & -1.268 & -0.7432 & -0.42122 \\
\hline Xist & 0 & -1.8355 & -0.0799 & -1.026 & -1.1511 & -1.601 \\
\hline $\operatorname{Igh}-6$ & 0 & 2.653 & 4.516 & 4.6602 & 3.895 & 4.22 \\
\hline Igh-6 & 0 & 4.9 & 5.6285 & 6.728 & 4.7308 & 6.277 \\
\hline$I g k$ & 0 & 3.0438 & 4.949 & 4.728 & 3.683 & 4.564 \\
\hline$I g k$ & 0 & 2.583 & 3.317 & 3.722 & 2.655 & 3.5134 \\
\hline Gabbrl & 0 & 1.283 & 0.662 & 1.4366 & 0.8659 & 0.295 \\
\hline Car4 & 0 & -1.193 & -0.8413 & -2.0376 & -1.153 & -0.5421 \\
\hline Ppara & 0 & -1.1158 & -0.767 & -0.9885 & -0.462 & -.0738 \\
\hline$X l r 4 a / b / c$ & 0 & -1.901 & 1.8709 & -1.056 & 0.4277 & -1.0978 \\
\hline Synj2 & 0 & 1.247 & 0.6407 & 1.154 & 1.2511 & 0.6854 \\
\hline$I g k$ & 0 & 2.119 & 2.997 & 3.451 & 2.4711 & 3.3166 \\
\hline Zdhh2 & 0 & -1.0832 & -0.678 & -1.121 & -1.083 & -0.278 \\
\hline Rps 24 & 0 & -0.9397 & 0.2292 & -1.359 & -0.9426 & -0.95638 \\
\hline Kank3 & 0 & -1.328 & -0.5902 & -1.684 & -1.272 & -1.31083 \\
\hline Syn 2 & 0 & -1.779 & -1.1061 & -1.985 & -1.854 & -0.09891 \\
\hline Ret & 0 & -2.7131 & -2.023 & -3.3322 & -3.155 & -0.82286 \\
\hline Prex 2 & 0 & -1.394 & -1.1882 & -2.0271 & -1.299 & -1.07016 \\
\hline $\operatorname{Pgm} 5$ & 0 & 1.672 & 1.256 & 2.0187 & 0.5574 & 0.92584 \\
\hline 9130214F15Rik & 0 & -1.4645 & -0.93309 & -1.973 & -0.8855 & 0.074 \\
\hline Camk2n1 & 0 & 0.8971 & 0.444 & 0.976 & 0.30126 & 0.5199 \\
\hline
\end{tabular}

Day 0 to Day 2: inclusion of the transient hypoglycaemia 'window' A set of 95 genes were differentially regulated at Day 2 following a transient window of hypoglycaemia that is first observed $24 \mathrm{~h}$ after c-Myc activation and extends for around $24 \mathrm{~h}$. These 95 genes included peroxisome proliferator-activating factor receptor $\gamma$ (Ppar $\gamma$ [also known as Pparg], down by twofold), $\operatorname{Veg} f \mathcal{c}$ (up by 2.8fold), endothelial differentiation gene 3 (Edg3) (down by 2.3-fold), Apoal (down by 3.3-fold), Egr (up by twofold), immunoglobin joining chain (Igj, upregulated by 3.5 -fold), cytochrome P450 (Cyp3a11, downregulated by threefold), albumin (Alb, downregulated by 4.9 -fold) and fatty acid binding protein 1 (Fabpl, downregulated by 4.29 -fold). The 69 of these genes that had recovered by the immediate time-point (Day 4) are regarded as exclusively regulated by the hypoglycaemia 'window'. These genes were included in the 95 genes that changed between Days 0 and 2. Among the hypoglycaemia-regulated genes are the putative homeodomain transcription factor 1 (Phtfl, down by twofold), collagen XII a1 (Col12a1, down by 2.41-fold), the genes encoding solute carrier families Slc35a5 and Slc9a3r2 (down by two- and 2.2-fold, respectively), and the chemokine C-X-C motif ( $\mathrm{Cxcl} 2$, up by tenfold).

Day 2 to Day 4: recovery from hypoglycaemia and early effects of hyperglycaemia During this period, the mice have recovered from the brief hypoglycaemia and on Day 4 have just started to become hyperglycaemic. Of the genes that were altered on Day 2, 69 (including those that specifically changed due to hypoglycaemia) had recovered by this time point, suggesting that the effects of transient hypoglycaemia are short-lived and recovered from within $48 \mathrm{~h}$. As only 26 of these genes had not recovered at Day 4, we can confidently exclude any significant residual effect of hypoglycaemia on the genes affected by hyperglycaemia.

On Day 4, a different subset of genes is now being affected, most probably due to onset of hyperglycaemia. 
Thus 169 genes not previously involved were deregulated at Day 4, including cell cycle- and growth-associated genes. Other genes included the upregulated apolipoprotein $\mathrm{E}$ (Apoe), collagen 1al (Colala1), angiogenin (Ang), Ppar $\gamma$ and the downregulated S100 protein, Cxcl2.

Day 4 to Day 7: effects of peak hyperglycaemia As the effects of hyperglycaemia become established, dramatic upregulation of genes encoding cytoskeletal proteins occurs, e.g. $\alpha$-actin (by 100-fold), Myh6, cardiac troponin c 1 (Tnnc1) and i 3 (Tnni3), and myozenin (Myoz). Other genes, e.g. apolipoprotein B (Apobec1), muscle creatine kinase $(\mathrm{Ckm})$, Wifl and prostaglandin endoperoxide synthase (Ptgs2) were also increased between early and peak hyperglycaemia. In total, 510 genes were altered during this phase of the experiment. Further comparative analyses also revealed a small group of 30 genes that may have been affected by hypoglycaemia and hyperglycaemia (Table 3 ). Examples of these are apolipoprotein D (Apod, upregulated), Ppara (also known as Ppara, downregulated) and fatty acid binding protein 4 (Fabp 4 , downregulated).

Day 7 to Day 11: early events immediately after initial reduction in blood glucose levels During this period blood glucose levels are declining, but have not yet normalised. Interestingly, a large proportion of genes (400) were downregulated from Day 7 to 11 (within 4 days of switching c-Myc off and during the process of reduction in blood glucose). Included in this group are $C c n d 2, M m p 3$, Vegfc, Myh6, Apobec2, Apod and Ckm. By Day 11, although the mice were still hyperglycaemic, all 'osteogenic' genes potentially involved in arterial calcification had returned to basal levels (Table 1 'Calcification genes').

Some genes remained altered on Day 11 and Day 26, when compared with Day 0. These are the non-reversed genes such as the upregulated Egrl and Fos, and the downregulated Plg, Ppary cla (also known as Ppargcla), leptin (Lep) and Fabpl.

Day 11 to day 26: early to established recovery This is a potentially very important group of genes $(n=331)$, as they include those that did not recover by the end of the study period. Examples are the upregulated T-box 20, prostaglandin $\mathrm{F}$ receptor (Ptger 3$)$ and heat shock protein 90 (Hsp90ab1), and the downregulated beta globin and interferon regulatory factor 4 (Irf4) (see also next section). As mentioned in the previous section, some genes already changed on Day 11 vs Day 0 continued to be altered on Day 26. More altered genes (non-reversed by Day 26) are Pthrl (upregulated), Apoal and Apobecl (downregulated).

Genes differentially expressed for the first time on Day 11 (early recovery) The expression of 57 genes, not previously altered by hyperglycaemia, changed after Day 11 . This group probably includes genes involved in the recovery from hyperglycaemia. Pathway analysis showed that the following processes are involved: apoptosis and cell cycle, fatty acid oxidation and gluconeogenesis (Ppary cla), glucose import (Fabp3) and atherosclerosis (Isll) (ESM Fig. 9).

Genes differentially expressed for the first time on Day 26 (established recovery) As the mice fully recovered from hyperglycaemia, a new group of genes changed for the first time on Day $26(n=69)$, such as cell cycle-related $R b m 3$ and cyclin D1 (Ccnd1), glutamate transporter (Slcla3), retinol dehydrogenase 11 (Rdh11), which is involved in cell growth, and Socs6 (involved in lipid biosynthesis) (ESM Fig. 10).

Verification of gene array data

Quantitative reverse transcriptase PCR was used to verify expression patterns of a selection of genes altered by glycaemia according to the array data. Examples were genes encoding key molecules implicated in cell cycle (Ccnd2), diabetes/insulin resistance (Ppar $\gamma)$ and cell adhesion (Vcaml) (Fig. 4). All quantitative reverse transcrip-

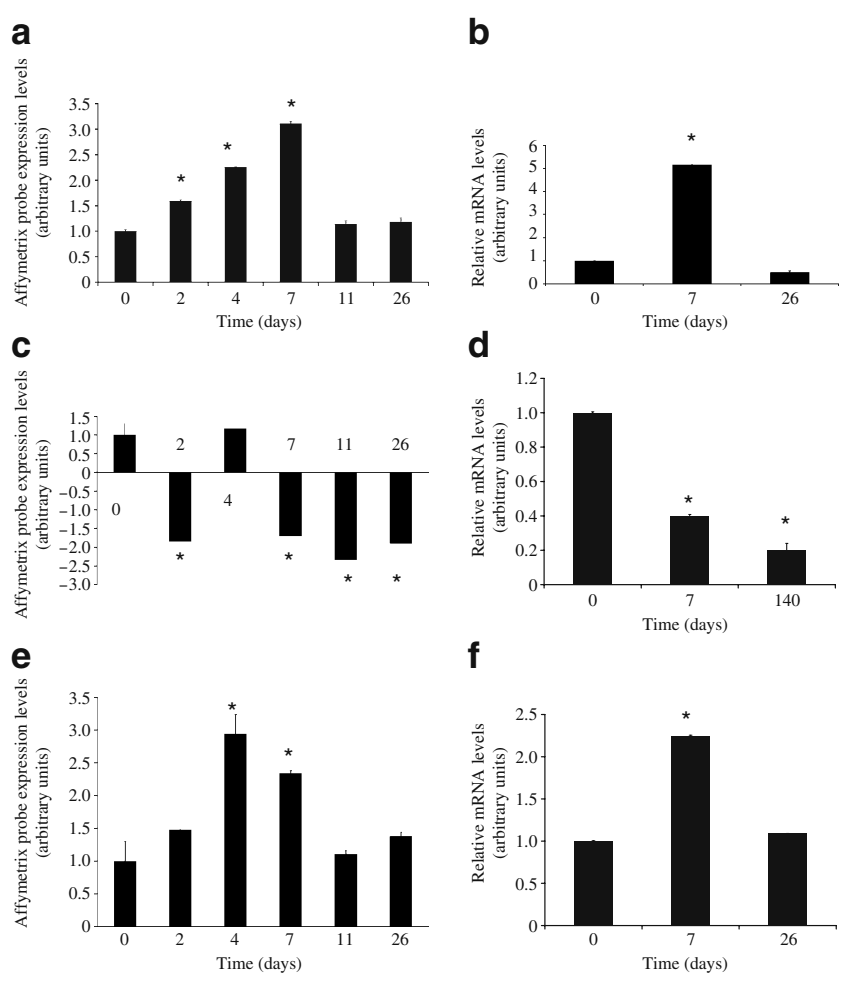

Fig. 4 Verification of GeneChip array results by quantitative real-time PCR, with gene expression profiles as Affymetrix data for (a) Ccnd2, (c) Ppary and (e) Vcam1, and as quantitative real-time-PCR for the same genes respectively $(\mathbf{b}, \mathbf{d}, \mathbf{f}) . p$ values for changes on Day 7 compared with Day 0 (Affymetrix data): $p=2.2 \mathrm{E}-03$ for $C c n d 2, p=$ $1.7 \times 10^{-2}$ for Ppary and $p=1.4 \times 10^{-3}$ for Vcam1. ${ }^{*} p<0.05$ 
tase PCR data confirmed the gene array results. Where necessary, later recovery time-points were analysed (Day 140).

\section{Immunohistochemistry}

We used standard fluorescence immunohistochemical techniques to study protein levels of vascular cell adhesion molecule (VCAM) 1 (cell adhesion-related), the atherosclerosis-related vascular endothelial growth factor (VEGF) and $\alpha$-actin (smooth muscle cell-related). Immunofluorescent signals increased in parallel to high glucose levels (Fig. 5).

\section{Discussion}

We examined immediate and early effects of relatively brief exposure of the artery to high glucose in $\mathrm{pIns-c-MycER}{ }^{\mathrm{TAM}}$ mice in vivo. Changes in arterial gene expression and to what extent these were reversible following recovery from hyperglycaemia were determined. For the first time, effects of hyperglycaemia were isolated from other potentially confounding metabolic factors and reversal studied without administration of glucose-lowering agents.

Fig. 5 Immunohistochemical analysis was performed to verify changes in protein levels of molecules shown to change at the gene level due to hyperglycaemia. These were examined on Days 0 (c-Myc 'OFF', prior to the onset of hyperglycaemia), 7 (c-Myc 'ON', hyperglycaemia) and 26 (c-Myc 'OFF', recovery). Immunofluorescence staining for VEGF, $\alpha$ actin and VCAM1 is shown. Blue, DAPI; green, antibody of interest recognising mouse VEGF, $\alpha$-actin and VCAM1, respectively. Scale bars $10 \mu \mathrm{m}$. Magnification VEGF, $\alpha$-actin $\times$ 400, VCAM $1 \times 200$
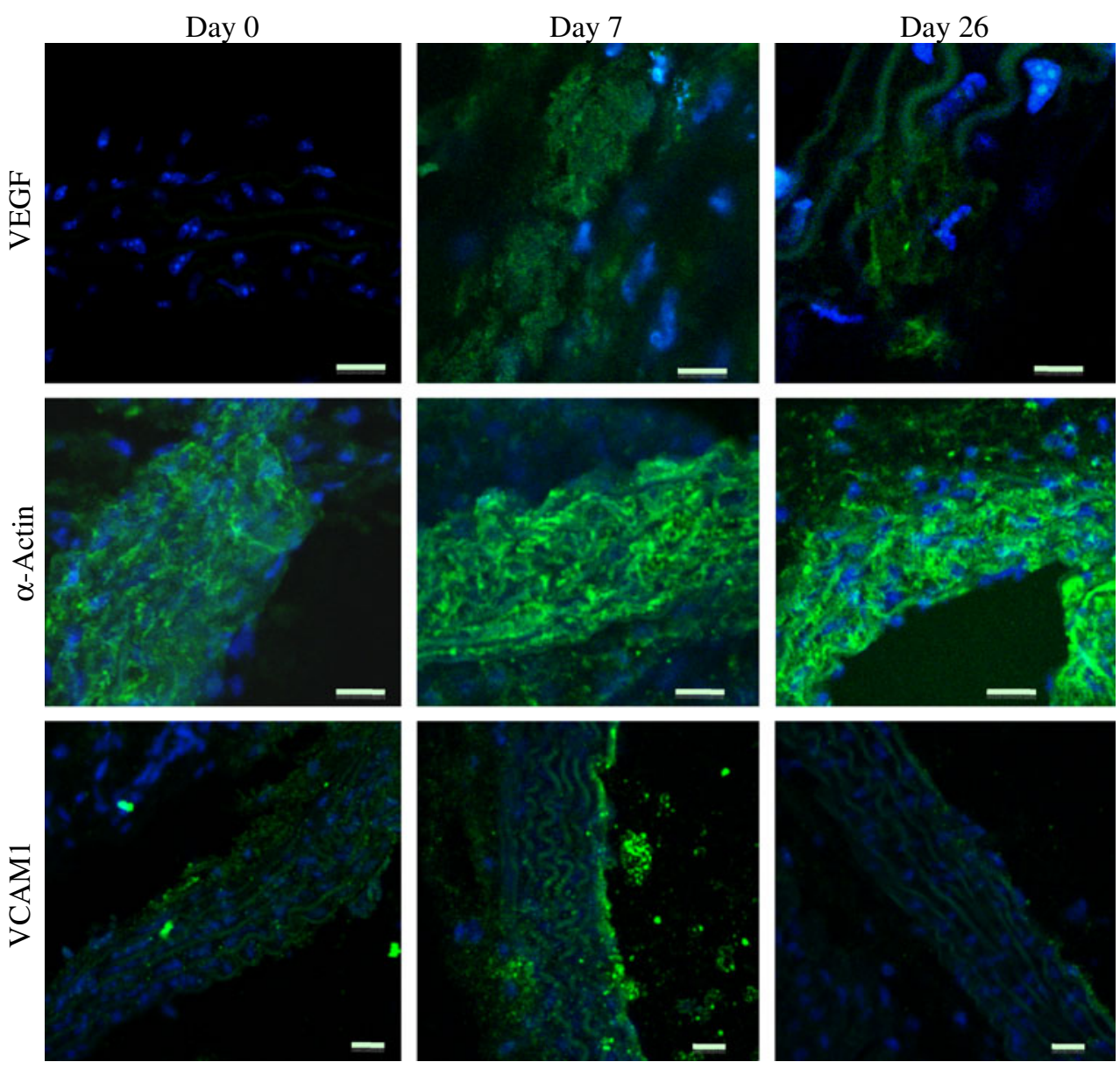
Transient hypoglycaemia significantly affects expression of 69 genes, including those involved in vascular function and differentiation, as well as in wound-healing and cholesterol metabolism, respectively [40-43]. The differential regulation of several atherosclerosis-relevant genes is very interesting in light of recent studies suggesting that symptomatic, severe hypoglycaemia is associated with an increased risk of myocardial dysfunction in the short term and in the long term may be implicated in cardiovascular dysfunction $[28,29]$. It is clear that transient hypoglycaemia in our in vivo model was accompanied by changed expression of various genes involved in vascular remodelling, vascular function and lipid metabolism; however these recovered fully within $48 \mathrm{~h}$ of recovery from hypoglycaemia. Importantly, genes regulated by hypoglycaemia appeared to be largely separate from those affected by hyperglycaemia, apart from a small subset of genes affected by both, such as Apod, Fabp4 and Ppara. As the overall number of genes affected is much smaller than that identified for hyperglycaemia, it is very unlikely that long-lasting effects of recovered hypoglycaemia affected our analyses.

Intriguingly, short periods of hyperglycaemia caused permanent changes in several genes that may play supportive roles in recovery from damage induced by glucose, such as Egrl (involved in wound-healing) and Slclaj (involved in glucose transport). However, this notion must be tempered by the persistent aberrant expression of genes that are implicated in on-going arterial damage, such as the oncogene Fos (which promotes an osteogenic profile in arterial cells), some which could be either beneficial or detrimental, e.g. plasminogen. It is worth noting that all of the calcification-related genes affected by hyperglycaemia had returned to normal expression in this study by Day 26 .

To our knowledge, this is the first time such changes have been shown as short-term consequences of hyperglycaemia in a fully controlled in vivo animal model of diabetes. In addition, these are the first data on the uncomplicated (pure) recovery from the arterial insult of hyperglycaemia in vivo without application of any glucoselowering agents, a crucial point given the controversy surrounding different potential actions/adverse effects of these agents themselves [12]. We can therefore use the animal model described here to begin unravelling the direct molecular effects of hyperglycaemia in vivo, as well as determining the extent to which simple reversal of the metabolic phenotype can reverse such effects.

Another point of interest is that we have shown that even after 4 months of recovery, a number of genes had still not reverted to Day 0 levels, as demonstrated by quantitative real-time PCR. This extends earlier suggestions from in vitro work with HUVECs that exposure of cells to continuous increased glucose results in a hyperglycaemic cellular memory [44]. One potential mechanism by which hyperglycaemia might cause such persistent changes has been suggested in a study showing that transient hyperglycaemia caused persistent epigenetic changes during subsequent normoglycaemia in cultured human aortic endothelial cells and after glucose infusion into nondiabetic mice [45].

In humans and most animal models, the very early stages of hyperglycaemia and diabetes have generally not been available for prospective studies. While vascular disease has previously been explored in the presence of multiple risk factors in the metabolic syndrome, we explored early changes in the artery caused solely by hyperglycaemia, the hallmark feature of diabetes, and isolated from other features of the cardiometabolic syndrome. Our findings provide a potential explanation why glucose-lowering treatments have been relatively ineffective in reducing CVD risk [11, 12], namely, that the deleterious effects of even short exposure to hyperglycaemia may be unexpectedly persistent at a molecular level.

Current guidelines for treating hyperglycaemia do not place sufficient emphasis on how quickly elevated blood glucose is corrected [46, 47]. As suggested by cell culture studies [48] and also by clinical studies, on-going arterial damage may develop undisturbed for long periods of time, leading to accelerated atherosclerosis and heart disease $[49,50]$. Our results provide strong direct in vivo support for these views, while highlighting for the first time some of the immediate effects of hyperglycaemia on the artery wall in vivo without any confounding effects of glucoselowering drugs.

Acknowledgements This work was funded by a Wellcome Trust project grant to M. Khan $(077683 / \mathrm{Z} / 05 / \mathrm{Z})$ and by an EC FP-7, MarieCurie IAPP to the ADIBET Consortium.

Duality of interest The authors declare that there is no duality of interest associated with this manuscript.

\section{References}

1. The Diabetes Control and Complications Trial Research Group (1993) The effect of intensive treatment of diabetes on the development and progression of longer complications in insulindependent diabetes mellitus. N Engl J Med 329:977-986

2. UK Prospective Diabetes Study (UKPDS) (1998) Group intensive blood-glucose control with sulphonylureas or insulin compared with conventional treatment and risk of complications in patients with type 2 diabetes. Lancet 352:837-853

3. Haffner SM, D'Agostino R Jr, Festa A et al (2003) Low insulin sensitivity $(\mathrm{S}(\mathrm{i})=0)$ in diabetic and nondiabetic subjects in the insulin resistance atherosclerosis study: is it associated with components of the metabolic syndrome and non-traditional risk factors? Diabetes Care 26:2796-2803

4. Milicevic Z, Raz I, Beattie SD, Campaigne BN, Sarwat S, Gromniak E (2008) Natural history of cardiovascular disease in patients with diabetes. Diabetes Care 31:S155-S160 
5. The ADVANCE Collaborative Group (2008) Intensive blood glucose control and vascular outcomes in patients with type 2 diabetes. New Engl J Med 358:2560-2572

6. Wei M, Gaskill SP, Haffner S, Stern MP (1998) Effects of diabetes and level of glycaemia on all-cause and cardiovascular mortality. The San Antonio Heart Study. Diabetes Care 21:1167-1172

7. Meigs JB, D’Agostino RB Sr, Nathan DM, Rifai N, Willson PW, Framingham Offspring Study (2002) Longitudinal association of glycaemia and microalbuminuria: the Framingham Offspring Study. Diabetes Care 25:977-983

8. Middelbeek RJ, Horton ES (2007) The role of glucose as an independent cardiovascular risk factor. Current Diabetes Rep 7:43-49

9. Rijkelijkhuizen JM, Nijpels G, Heine RJ, Bouter LM, Stehouwer CD, Dekekr JM (2007) High risk of cardiovascular mortality in individuals with impaired fasting glucose is explained by conversion to diabetes: the Hoorn study. Diabetes Care 30:332-336

10. Juutilainen A, Lehto S, Rönnemaa T, Pyörälä K, Laakso M (2008) Similarity of the impact of type 1 and type 2 diabetes on cardiovascular mortality in middle-aged subjects. Diabetes Care 31:714-719

11. Home PD, Pocock SJ, Beck-Nielsen H et al (2005) Rosiglitazone evaluated for cardiac outcomes and regulation of glycaemia in diabetes (RECORD): study design and protocol. Diabetologia 48:1726-1735

12. Nissen SE, Wolski K (2007) Effect of rosiglitazone on the risk of myocardial infarction and death from cardiovascular causes. $\mathrm{N}$ Engl J Med 356:2457-2471

13. Donnini D, Del Terra E, Ambesi-Impiombato FS, Gurcio F (2003) New in vitro model to study high glucose-dependent endothelial dysfunctions. Biochimie 85:701-705

14. Otsuka A, Azuma K, Iesaki $T$ et al (2005) Temporary hyperglycaemia provokes monocyte adhesion to endothelial cells in rat thoracic aorta. Diabetologia 48:2667-2674

15. Quagliaro L, Piconi L, Asaloni R et al (2005) Intermittent high glucose enhances ICAM-1, VCAM-1 and E-selectin expression in human umbilical vein endothelial cells in culture: the distinct role of protein kinase $\mathrm{C}$ and mitochondrial superoxide production. Atherosclerosis 183:259-267

16. Christ M, Bauersachs J, Liebetrau C, Heck C, Gunther A, Wehling M (2002) Glucose increases endothelial-dependent superoxide formation in coronary arteries by $\mathrm{NAD}(\mathrm{P}) \mathrm{H}$ oxidase activation: attenuation by the 3-hydroxy-3-methylglutaryl coenzyme A reductase inhibitor atorvastatin. Diabetes 51:2648-2652

17. Garcia Soriano F, Viraq L, Jagtap P, Szabo et al (2001) Diabetic endothelial dysfunction: the role of poly(ADP-ribose) polymerase activation. Nat Med 7:108-113

18. Kunlathoor VV, Wilson DL, LeBoeuf RC (1996) Increased atherosclerosis in streptozotocin-induced diabetic mice. J Clin Invest 97:1767-1773

19. Renard C, Van Obberghen E (2006) Role of diabetes in atherosclerotic pathogenesis. What have we learned from animal models? Diabetes Metabol 32:15-29

20. Wendt T, Haria E, Bucciarelli L et al (2006) RAGE modulates vascular inflammation and atherosclerosis in a murine model of type 2 diabetes. Atherosclerosis 185:70-77

21. Goldberg IJ, Dansky HM (2006) Diabetic vascular disease: an experimental objective. Atheroscler Thromb Vasc Biol 26:16931701

22. Werstuck GH, Khan MI, Femia G et al (2006) Glucosamineinduced endoplasmic reticulum dysfunction is associated with accelerated atherosclerosis in a hyperglycemic mouse model. Diabetes 55:93-101

23. Tochino Y (1987) The NOD mouse as a model of type I diabetes. Crit Rev Immunol 8:49-81

24. Bailey CJ, Flatt PR (1987) Increased responsiveness to glucoregulatory effect of opiates in obese-diabetic ob/ob mice. Diabetologia 30:33-37
25. Bolzan AD, Bianchi MS (2002) Genotoxicity of streptozotocin. Mutat Res 512:121-134

26. Pelengaris S, Littlewood T, Khan M, Elia G, Evan G (1999) Reversible activation of c-Myc in skin: induction of a complex neoplastic phenotype by a single oncogenic lesion. Mol Cell 3:565-577

27. Pelengaris S, Khan M, Evan G (2002) Suppression of Mycinduced apoptosis in beta cells exposes multiple innate oncogenic properties of Myc sufficient to trigger immediate carcinogenic progression. Cell 109:321-334

28. Desouza C, Salazar H, Cheong B, Murgo J, Fonseca V (2003) Association of hypoglycaemia and cardiac ischemia A study based on continuous monitoring. Diabetes Care 26:1485-1489

29. Bonds DE, Miller ME, Bergenstal RM et al (2010) The association between symptomatic, severe hypoglycaemia and mortality in type 2 diabetes: retrospective epidemiological analysis of the ACCORD study. BMJ 340:b4909

30. Karteris E, Zervou S, Pang Y et al (2006) Progesterone signaling in human myometrium through two novel membrane $G$ proteincoupled receptors: potential role in functional progesterone withdrawal at term. Mol Endocrinol 20:1519-1534

31. Wu Z, Irizarry RA (2004) Preprocessing of oligonucleotide array data. Nat Biotech 22:656-658

32. Livak KJ, Schmittgen TD (2001) Analysis of relative gene expression data using real-time quantitative PCR and the $2^{-\Delta \Delta C t}$ method. Methods 25:402-408

33. Pascal SM, Guiot Y, Khan PS, Jonas JC M (2008) Effects of c-MYC activation on glucose stimulus-secretion coupling events in mouse pancreatic islets. Am J Physiol Endocrinol Metab 295: E92-E102

34. Maizel J, Six I, Slama M et al (2009) Mechanisms of aortic and cardiac dysfunction in uremic mice with aortic calcification. Circulation 119:306-313

35. Cleary PA, Orchard TJ, Genuth S, Wong ND, Detrano R, Backlund JY, DCCT/EDIC Research Group et al (2006) The effect of intensive glycemic treatment on coronary artery calcification in type 1 diabetic participants of the Diabetes Control and Complications Trial/Epidemiology of Diabetes Interventions and Complications (DCCT/EDIC) Study. Diabetes 55:3556-3565

36. Chen NX, Moe SM (2003) Arterial calcification in diabetes. Curr Diab Rep 3:28-32

37. Cola C, Almeida M, Li D, Romeo F, Mehta JL (2004) Regulatory role of endothelium in the expression of genes affecting arterial calcification. Bioch Biophys Res Com 320:424-427

38. Schiffrin EL, Lipman ML, Mann JF (2007) Chronic kidney disease: effects on the cardiovascular system. Circulation 116:85-97

39. Cano DA, Rulifson IC, Heiser PW et al (2007) Regulated beta-cell regeneration in the adult mouse pancreas. Diabetes 57:958-966

40. Cheung L, Zervou S, Mattsson G et al (2010) c-Myc directly induces both impaired insulin secretion and loss of beta cell mass, independently of hyperglycaemia in vivo. Islets $2: 1-9$

41. Duan SZ, Usher MG, Mortensen RM (2008) Peroxisome proliferator-activated receptor-gamma-mediated effects in the vasculature. Circ Res 102:283-294

42. Matsui T, Yamagashi S, Takeuchi M, Ueda S, Fukami K, Okuda S (2009) Nifedipine, a calcium channel blocker, inhibits advanced glycation end product (AGE)-elicited mesangial cell damage by suppressing AGE receptor (RAGE) expression via peroxisome proliferator-activated receptor-gamma activation. Biochem Biophys Res Commun 385:269-272

43. Schnabel R, Dupuis J, Larson MG et al (2009) Clinical and genetic factors associated with lipoprotein-associated phospholipase A2 in the Framingham Heart Study. Atherosclerosis 204:601-607

44. Strang AC, Hovingh GK, Stroes ES (2009) Kastelein JJ (2009) The genetics of high-density lipoprotein metabolism: clinical relevance for therapeutic approaches. Am J Cardiol 104:22E-31E 
45. Corgnali M, Piconi L, Ihnat M, Ceriello A (2007) Evaluation of gliclazide ability to attenuate the hyperglycaemic 'memory' induced by high glucose in isolated human endothelial cells. Diab Metab Res Rev 24:301-309

46. El-Osta A, Brasacchio D, Yao D et al (2008) Transient high glucose causes persistent epigenetic changes and altered gene expression during subsequent normoglycaemia. J Exp Med 205:2409-2417

47. Nathan DM, Buse JB, Davidson MB et al (2006) Management of hyperglycaemia in type 2 diabetes: a consensus algorithm for the initiation and adjustment of therapy. A consensus statement from the American Diabetes Association and the European Association for the Study of Diabetes. Diabetologia 49:1711-1721

48. National Collaboration Centre for Chronic Conditions (2008) Type 2 diabetes: national clinical guideline for management in primary and secondary care (update). Royal College of Physicians, London

49. Ihnat MA, Thorpe JE, Kamat CD et al (2007) Reactive oxygen species mediate a cellular 'memory' of high glucose stress signalling. Diabetologia 50:1523-1531

50. Ceriello A, Esposito K, Piconi L et al (2008) Oscillating glucose is more deleterious to endothelial function and oxidative stress than mean glucose in normal and type 2 diabetic patients. Diabetes 57:1349-1354 